\title{
Distributive Politics, Nature of Government Spending and Economic Growth in a Low Income Democracy*
}

\section{Políticas distributivas, naturaleza del gasto gubernamental y crecimiento económico en democracia con bajos recursos}

\author{
Joydeb Sasmal ${ }^{1}$
}

Received: October 6, 2010

Accepted date: February 3, 2011

\begin{abstract}
In this paper we analyze how the government in a democratic setup of the developing world manipulates the fiscal instruments to maximize its political gain so that it can retain power. The government and the voters in low income countries are generally selfish and myopic in the sense that the electorates prefer to get direct and immediate benefits from the government while the government, in turn, tries to seek majority support in the election, by adopting short term and distributive policies instead of going for long term growth. Using the theoretical structure of the existing literature, and making modifications therein, this study demonstrates that the optimal tax rate, public expenditure shares and growth rate are determined in terms of technological and behavioral parameters. The simulation results show that if political gain from distributive policies is high, the government will allocate a greater share of the fund for distributive purposes adversely affecting economic growth.
\end{abstract}

Keywords: Selfish government, fiscal instruments, distributive policies, political gain, long term growth.

\section{Resumen}

Este trabajo analiza cómo el gobierno, en el contexto democrático de los países en desarrollo, manipula los instrumentos fiscales para maximizar su ganancia política con el fin de retener el poder. El gobierno y los votantes en países pobres son generalmente egoístas y miopes en el sentido de que el electorado prefiere conseguir beneficios directos e inmediatos del gobierno, mientras que el gobierno, a su vez, trata de obtener la mayor cantidad de partidarios en una elección, mediante la adopción de políticas distributivas y de corto plazo en vez de elegir el crecimiento a largo plazo. Aplicando el marco teórico de la literatura existente, y realizando algunas modificaciones en ellas, este estudio demuestra que la óptima tasa de impuestos, las cuotas de gasto público y la tasa de crecimiento se establecen sobre la base de parámetros tecnológicos y de conducta. Los resultados de la simulación demuestran que si el beneficio político de estas políticas distributivas es alto, el gobierno asignará una parte sustanciosa de los fondos con propósitos distributivos afectando contrariamente el crecimiento económico.

Palabras clave: Gobiernos egoistas, instrumentos fiscales, políticas distributivas, ganacia política, crecimiento a largo plazo plazo.

* The author is in debt to Professor Sugata Marjit, Professor Asis Kumar Banerjee and Sayan Mukherjee for their comments and help in writing this paper. He expresses his gratitude and indebtedness to the anonymous referee for very fruitful comments on this paper. The author is also grateful to the Editor and Managing Editor for their suggestion and help in the submission of this paper.

1. Ph.D. in Economics. Associate Professor of Economics, K.K. Das College, University of Calcutta, India.

<joydebsasmal@yahoo.co.in>. 


\section{INTRODUCTION}

The role of the government in economic development, optimal size of the government, nature of government spending and its impact on growth, public expenditure and corruption, distributive politics and economic growth have become important issues in the literature of public policy and fiscal management (Alesina \& Rodrik, 1994; Meltzer \& Richard, 1981; Persson \& Tabellini, 1994). Often we talk about optimal fiscal policy, benevolent government and maximization of growth. But maximization of growth may not be the main objective of the government. Instead, the government may be more interested in increasing its political gain by manipulating fiscal instruments to remain in power. The government, especially in the developing world, very often strategically adopts short term populist measures and resorts to distributive policies sacrificing long term growth (Sasmal, 2004; Marjit, Kolmar \& Mukherjee, 2001; Marjit \& Maity, 2006). Both the political parties and electorates are generally selfish and myopic in a low income democracy in the sense that the voters like to get direct and immediate benefits from the government while the government tries to stay in power compromising the future economic growth and fiscal discipline. It may sound unusual that growth is not always necessary to retain power in the government. Political stability can very well co-exist with economic stagnation in a democratic setup (Sarkar, 2006). Equally, taxation and government spending is not the only mechanism for income transfer. Informal economy and weak governance can be an alternative route through which redistribution of income can take place (Marjit, Mukherjee \& Kolmar, 2006). Marjit, Kolmar \& Mukherjee (2001) demonstrate that the greater the scope for redistribution politics, the worse will be the quality of public investment.

The median voter theory tells that if inequality is high there will be a demand for large government which adversely affects economic growth (Alesina \& Rodrik, 1994). But it is not only the poor who favor redistribution and direct and immediate benefits from the government. The well-off groups, like business groups, big farmers, beaurocrats, government employees and other interest groups are also very keen to extract maximum benefits directly and immediately from the government in the forms of subsidies, salaries, allowances and other concessions, although such expenses are not always unproductive altogether. So, given the preference of the people and the political compulsion of seeking majority support in a democratic set up, the government is rather forced to adopt populist short term measures, which may not be helpful for long term growth. However, this particular nature of fiscal decisions and their impact on growth are not discussed in the literature in that sense, especially in the context of developing countries. Contrary to the median voter theory, the papers by Banerjee \& Newman (1993) and Galor \& Zeira (1993) indicate the possibility of a different result. The argument is that if redistributive policies can enhance human capital, they may not be growth retarding.

Our common wisdom suggests that long term investment on road, railways, airport and highways, irrigation, electricity, telecommunications, education, health, science and technology and other infrastructural facilities accelerate economic growth. However, empirical studies exhibit mixed results. In Devarajan et al. (1996) and Ghosh \& Gregoriou (2008) current expenditure has been found to be more productive than capital expenditure, while in Chen (2006) the result is different. The studies based on cross-country data are too aggregative in nature and they overlook many local factors. So, more scientific and in-depth studies, preferably in disaggregated form, are necessary to capture the effect of public expenditure on growth in a proper way. Whether the effects of government spending will be reflected in the growth process depends not only on the composition of public expenditure, but also on the nature of growth, time span of completing the public projects and proper mechanism of transmitting the external effects of the expenses to growth. It may happen that the nature of public spending may matter little in the process of economic growth.

Here, it is necessary to differentiate between the fiscal management in a developed economy and that in the developing world. There is a very standard and 
flourishing literature on the optimal tax rate, composition of public expenditure and economic growth. However, research on the behavior of the government with respect to fiscal decisions and their impact on economic growth in the democratic set up of the developing world are relatively scanty. Marjit \& Maity (2006) and Marjit, Mukherjee and Kolmar (2006) have some important contributions in this field. Sasmal (2002, 2004, 2007) finds that if proportion of poor people is higher in a society, the government will resort to more redistributive policies with its negative implication for long-term growth. In this paper, we like to contribute to this literature by analyzing the behavior of the government in the determination of the tax rate and nature of government spending in a low income democracy keeping in mind that the objective of the government is maximization of political gain, although the social welfare is not altogether neglected. The present study makes a neoclassical treatment of fiscal management where the government acts as an optimizing agent to maximize its self interest subject to the constraints imposed by the preference of the electorates and the production technology. This work also intends to examine the impact of policy decisions of the government on economic growth in an endogenous framework using the structure of the existing literature and making modifications therein to fit the purpose of this paper. In this exercise, the Barro Model (1990) has been modified by inserting two types of government expenditures into the production function and an element of corruption in the budgetary allocations to derive new results. Two types of government expenditures are: (i) investment for long term growth $\left(G_{1}\right)$, and (ii) expenditure for distributive politics $\left(G_{2}\right)$. It demonstrates that corruption and expenditure on distributive politics lower the growth rate. According to the Barro Model, the tax rate $(r)$ and expenditure shares of $G_{1}$ and $G_{2}$ are exogenously given and constant over time. In Ghosh \& Gregoriou (2008) the optimal tax rate and capital and current expenditure shares are determined endogenously in terms of technological and behavioral parameters and the decision variables, although determined endogenously, are constant. The results show that the impact of $r, G_{1}$ and $G_{2}$ on the rate of growth depends on the parameters. To demonstrate how the government determines the optimal tax rate and public expenditure shares to maximize its political gain and to examine the effect of government decisions on economic growth, this paper has made some modifications in the model of Agenor (2008). The results of the modifications show that if $G_{2}$ generates greater political mileage, the government will be inclined to allocate more funds to $G_{2}$ undermining long term growth.

The whole paper has been arranged as follows: the first section presents the theoretical models and their modifications to derive new results with respect to the optimal tax rate and nature of public spending and their impact on economic growth. It is followed by an exercise of simulation on the effect of two important parameters capturing the political mileage from distributive spending on economic growth. After theoretical discussion, some empirical information from the Indian situation has been presented to give an idea of the nature of public spending in the largest democracy of the world. However, no econometric analysis using Indian data has been done. In the last section, we present the conclusions and summary results of this paper.

\section{THEORETICAL FRAMEWORK}

\section{Endogenous Growth with Government Spending}

Accumulation of capital, growth of labor force and technical progress are generally considered as the major three forces of long term growth in a country. Many factors are taken exogenous to the growth process. If growth takes place due to technical progress coming from outside the production system, as has been explained in Harrod \& Solow models, it is called exogenous technical progress. But it may very well be endogenous to the system. More specifically, it may be the result of some purposeful activities of R\&D by any private agency or by the government within the system. In later period, particularly in the mid-1980s, a group of growth theorists led by Romer (1986, 1990), constructed a class of growth models in which the key determinants of growth have been shown to be endogenously determined by the optimizing agents within the system. As growth is determined by endogenously 
determined factors in such models, it is called endogenous growth (Barro \& Sala-i-Martin, 1995). In Harrod and Solow models, saving rate is exogenously given. But in Ramsey model, rates of saving and capital formation are determined by the optimizing behavior of the households. Optimal rates of saving and capital accumulation (Ramsey, 1928), population growth (Barro \& Becker, 1989), accumulation of knowledge and human capital (Romer, 1986, 1990; Uzawa, 1965), optimal allocation of resources to R\&D for technical progress (Grossman \& Helpman, 1991) are the main works of new growth theories. Endogenous growth models not only endogenously determine the key factors of growth, but also provide mechanism in which interaction of the behavior of optimizing agents in the system determines the optimal path of growth of the key determinants of growth as well as the path of economic growth over time. The implication of endogenous growth in this paper is to conceive the government as an optimizing agent to determine the fiscal variables in an endogenous framework to trace out the growth path.

One important requirement of endogenous growth is the elimination of diminishing returns to capital. The problem with the Solow model is that if capital per unit of labor $(\mathrm{K} / \mathrm{L})$ written as $\mathrm{k}$ rises marginal product of capital declines (Inada condition). But, if the returns to capital can be stopped from declining, growth can be perpetuated and that can be done by continuous growth of human capital, knowledge and technical progress by necessary investment and $R \& D$ activities in an endogenous framework. The empirical findings of economic growth in different countries in recent years strongly support this view. The idea of non-diminishing returns to capital is quite plausible if we think of capital in a broader perspective to include human capital. Human capital apart, endogenously developed technical progress or accumulation of knowledge can stop returns to capital from falling. The endogenous growth model can be built up both in the context of constant and increasing returns to capital. The simple model in this category with constant returns to capital is AK model (Barro \& Salai-Martin, 1995). The important model with increasing returns to capital in endogenous framework has been developed by Romer (1986) and Rebelo (1991).
The government can accelerate growth by playing an important role in the development of infrastructure, human capital, knowledge and technology. Barro (1990), Alesina \& Rodrick (1994) and Barro \& Salai-Martin have explained how government spending both on production and consumption affects long term growth. Obviously, tax rate, allocation of funds for productive investments and distributive politics, as well as corruption in the government level, have become important in the growth process.

As stated before, we apply in this study the Barro Model with some modifications. The differences are on two points: (i) unlike Barro, the present work considers a model where government distributes its funds on two broad heads: (a) expenditure for long term development $\left(\mathrm{G}_{1}\right)$ and (b) expenditure on distributive politics $\left(G_{2}\right)$. We assume both types of expenditures raise productivity, but $G_{1}$ is more productive than $G_{2}$. This model shows that if government has to allocate a greater share of the funds to $\mathrm{G}_{2}$ to meet its political compulsions, growth rate will be lower in the country. (ii) Leakage of fund due to corruption lowers the growth rate.

\section{AN OUTLINE OF THE BARRO MODEL}

Endogenous growth with government spending as described in Barro and Barro \& Sala-i-Martin has specified production function in Cobb-Douglas form:

(1) $\mathrm{Y}=\mathrm{AK}^{\alpha} \mathrm{L}^{1-\alpha} \mathrm{G}^{1-\alpha}$,

where $\mathrm{G}$ is productive public good financed by equal amount of tax collection, $\mathrm{Y}$ is output, $\mathrm{K}$ is private capital, $\mathrm{L}$ is labour and $\mathrm{A}$ is a constant term. $\mathrm{G}$ is government's total purchase of private output that is used for development of physical infrastructure, human capital, law and order etc. $G$ is of public good nature in the sense that it is non-rival and non-excludable. Congestion effects in public good services are ruled out here.

Now, equation (1) can be written as follows:

(2) $\mathrm{Y}=\mathrm{AK}^{\alpha}(\mathrm{LG})^{1-\alpha}$ 
This is a constant return to scale production function with diminishing returns to a single factor. Assuming $\mathrm{L}$ as constant, if $\mathrm{G}$ is kept unchanged, the function exhibits diminishing returns to $\mathrm{K}$. But if $\mathrm{G}$ increases at the same rate as $\mathrm{K}$, the function shows constant returns in $\mathrm{K}$ and $\mathrm{G}$, and as a result the economy becomes capable of having endogenous growth.

Here, the government follows a balanced budget policy and a proportional tax rate, i.e.:

(3) $\mathrm{G}=\mathrm{r} Y$,

where $r$ is the rate of tax. It is assumed that tax rate (r) and government expenditure - income ratio $(\mathrm{G} / \mathrm{Y})$ are constant over time.

Profit maximization conditions of firms require that (i) wage rate $(\mathrm{W})$ equals the after-tax marginal product of labor, and (ii) rental rate (R) equals the after tax marginal product of capital. That is,

$$
\mathrm{R}=(1-\mathrm{r}) . \delta \mathrm{Y} / \delta \mathrm{K}=(1-\mathrm{r}) \alpha \mathrm{Ak}^{-(1-\alpha)} \mathrm{G}^{1-\alpha}
$$

Solving $\mathrm{G}$ from the production function in (1) and substituting the value in (4), we get,

$$
R=(1-r) \alpha A^{\alpha}(\operatorname{Lr})^{(1-\alpha) / \alpha}
$$

$\mathrm{R}$ is now independent of $\mathrm{k}$, and given the values of $\mathrm{A}$, $\mathrm{L}, \mathrm{r}, \alpha$, rental rate $(\mathrm{R})$ is constant, i.e. $\mathrm{MP}_{\mathrm{K}}$ is constant. So the requirement of endogenous growth is met.

\section{Ramsey Model of Optimal Saving and Capital Accumulation:}

Following Barro \& Sala-i-Martin, we can explain the Ramsey model here. This model considers the problem of maximization of intergenerational utility of households over an infinite time horizon. It assumes a constant elasticity utility function, i.e. elasticity of intertemporal substitution in consumption is constant. Population growth rate (n) is exogenous and discount rate of utility from future consumption $(\rho)$ is also constant. Per capita consumption is $c(t)=\frac{C(t)}{L(t)}$ where $\mathrm{C}(\mathrm{t})$ and $\mathrm{L}(\mathrm{t})$ are total consumption and total population respectively in period $\mathrm{t}$. $\mathrm{L}(\mathrm{t})=\mathrm{e}^{\mathrm{nt}}$ and $\mathrm{L}(\mathrm{O})=1$.

The objective of each household is to maximize overall utility

$$
U=\int_{0}^{\infty} u[c(t)] e^{n t} e^{-\rho t} d t
$$

The utility function is $u(c)=\frac{c^{1-\theta}-1}{1-\theta}, \theta>0$, where $\theta$ is the elasticity of marginal utility w.r.t. per capita consumption.

The flow budget constraint of the household is: $\dot{a}=W+R a-c-n a$, where $a$ is net asset per person.

Now, the dynamic optimization problem can be solved with the present value Hamiltonian as follows:

$$
H=u(c) e^{-(\rho-n) t}+v[W+(R-n) a-c]
$$

where $v$ is the present value shadow price of income, F.O.C. for maximization of $U$ are

(6) $\frac{\delta H}{\delta c}=u^{\prime}(c) e^{-(\rho-n) t}-v=0$

(7) $-\frac{\delta H}{\delta a}=\dot{\mathrm{v}}=-(R-n) v$

And transversality condition is

$$
\lim _{t \rightarrow \infty}[v(t) \cdot a(t)]=0
$$

By using Euler equation conditions (6) and (7) can be reduced to

(8) $R=\rho-\left[\frac{u^{\prime \prime}(c) \cdot c}{u^{\prime}(c)}\right]\left(\frac{\dot{c}}{c}\right)$ where $\left[\frac{u^{\prime \prime}(c) \cdot c}{u^{\prime}(c)}\right]$ can be

termed as elasticity of $u^{\prime}(c)$ w.r.t. c. It can also be called the reciprocal of the elasticity of inter-temporal substitution $(\sigma)$. Assuming $\sigma$ asymptotically constant we have a steady state with $\mathrm{R}$ and $\frac{\dot{c}}{c}$ constant. 
From the utility function stated above, it follows $\sigma=\frac{1}{\theta}$ where $\theta>0$. Using this result, equation (8) can be simplified to $g_{c}=\frac{\dot{c}}{c}=\frac{1}{\theta}(R-\rho)$.

Differentiation of (6) w.r.t. time $(t)$ and substitution of the value in $\dot{v}$ in (7) gives the result $\frac{\dot{c}}{c}$ in (8). Putting the value of $\mathrm{R}$ from (5) we can write

$$
g_{c}=g_{y}=\frac{\dot{y}}{y}=\frac{\dot{c}}{c}=\frac{1}{\theta}\left[\alpha A^{\frac{1}{\alpha}}(r L)^{\frac{1-\alpha}{\alpha}}(1-r)-\rho\right]
$$

in a steady state growth.

Equation (9) signifies that $r$ affects growth rate through two channels: $(1-r)$ represents negative effect of taxation on the growth rate whereas $(r) \frac{1-\alpha}{\alpha}$ represents a positive impact on the growth rate through higher productivity. Barro concludes that if $r$ is low, the second effect dominates the first, and if $r$ is high the result is reversed. If the government is a benevolent one, then the growth maximizing tax rate will be consistent with the maximization of utility of the households over time through Cobb-Douglas production function and growth maximizing tax rate will be fixed at $r=1-\alpha$.

\section{MODIFICATION OF THE BARRO MODEL}

In the basic model of Barro, the government spends the whole amount of tax collection on productive service. In an extension of the model, a situation has been considered where the government spends a part of the tax revenue for consumption of the households and of the government itself. Here, growth rate over time has been found to be lower than what it would have been if the entire tax-revenue were used for productive purposes.

The modification of the model also assumes a balanced budget policy. But the tax-revenue is spent on two heads as mentioned earlier: (i) expenditure on long-term development $\left(\mathrm{G}_{1}\right)$, and (ii) expenditure on distributive politics $\left(\mathrm{G}_{2}\right)$. Chen (2006) considered productive and consumptive expenditures in the budget. The consumptive expenditure has no role in production. As in Devarajan et al. (1996) and Ghosh \& Gregoriou (2008), in the present modification also both $\mathrm{G}_{1}$ and $\mathrm{G}_{2}$ are productive, but $\mathrm{G}_{2}$ is assumed to be less productive than $G_{1}$. Here, the government spending on redistributive politics includes a wide variety of expenditures ranging from direct transfers and subsidies to the poor to various concessions and leverages to different interest groups of the country. This is done to meet the government's electoral compulsions. It is important to note that these expenditures are not totally unproductive. Our assumption is that such expenditures enhance productivity through nutritional efficiency, human skill, greater incentives and involvement in the production process. However, their impact on production is less than that of long term investment. We have considered a Cobb-Douglas production function in which both $\mathrm{G}_{1}$ and $\mathrm{G}_{2}$ have been included as productive factors in addition to private capital and labor, i.e.,

$$
\mathrm{Y}=\mathrm{AK}^{\alpha} \mathrm{G}_{1}{ }^{\beta}\left(\mathrm{LG}_{2}\right)^{1-\alpha-\beta}
$$

$\mathrm{K}$ is private capital, $\mathrm{L}$ is labor and $\mathrm{Y}$ is output and

$$
\frac{\partial Y}{\partial G_{1}}>\frac{\partial Y}{\partial G_{2}}
$$

$\mathrm{L}$ is assumed to be constant as before. $\mathrm{L}$ remaining constant, if $\mathrm{G}_{1}$ and $\mathrm{G}_{2}$ are increased at the same rate with $\mathrm{K}$, there will be constant returns to scale in production. $L$ and $G_{2}$ are perfect substitutes. Actually, here labor is being measured in efficiency terms and it is assumed that $\beta>1-\alpha-\beta$.

Since the government follows a balanced budget policy, total tax collection $(\mathrm{T})$ is equal to total government spending $(\mathrm{G})$ i.e. $\mathrm{T}=r . Y=\mathrm{G}=\mathrm{G}_{1}+\mathrm{G}_{2}$.

Let us assume that $r, \lambda$ and $\psi$ are respectively tax rate, share of government-spending for long term investment and share of leakage of government fund due to corruption and they are given and constant over time. So, the net available fund with the government is:

$$
\lambda(1-\psi) \cdot r \cdot Y+(1-\lambda)(1-\psi) \cdot r \cdot Y=(1-\psi) \cdot r \cdot Y
$$


Equation (5) can be used for incorporating government policy into the growth model through equation (11).

Now to find $\mathrm{MP}_{\mathrm{K}}$, let us consider the production function in equation (1):

$$
\mathrm{Y}=\mathrm{AK}^{\alpha} \mathrm{G}_{1}{ }^{\beta}\left(\mathrm{LG}_{2}\right)^{1-\alpha-\beta}
$$

In per capita terms it reduces to

(12) $\left.y=A k^{\alpha} g_{1}^{\beta} G_{2}\right)^{1-\alpha-\beta}$

$\mathrm{MP}_{\mathrm{K}}$ can be derived from equation (12) as follows:

$$
\begin{aligned}
& \mathrm{MP}_{\mathrm{K}}=\frac{\partial Y}{\partial K}=L \cdot A \cdot g_{1}{ }^{\beta} G_{2}{ }^{1-\alpha-\beta} \alpha k^{\alpha-1} \cdot \frac{\partial k}{\partial K} . \\
& =A g_{1}{ }^{\beta} G_{2}{ }^{1-\alpha-\beta} \alpha k^{-(1-\alpha)}
\end{aligned}
$$

From equation (11) we can write

$$
g_{1}=\frac{G_{1}}{L}=\frac{1}{L} \cdot \lambda(1-\psi) r . Y
$$

and, $G_{2}=(1-\lambda)(1-\psi) Y$.

Inserting the value of $g_{1}$ and $G_{2}$ in (13) we get

$$
\mathrm{MP}_{\mathrm{K}}=\alpha A^{\frac{1}{\alpha}} \lambda^{\frac{\beta}{\alpha}}(1-\lambda)^{\frac{1-\alpha-\beta}{\alpha}}[(1-\psi) r]^{\frac{1-\alpha}{\alpha}} L^{\frac{\beta}{\alpha}}
$$

(see Appendix).

Here also, $\mathrm{MP}_{\mathrm{K}}$ is independent of $\mathrm{k}$ and it is constant given the parameters and the given values of $r, \lambda$ and $\psi$. It suggests that $\mathrm{MP}_{\mathrm{K}}$ depends on technological parameters and the given values of $\lambda, \psi$ and $r$.

Now equating rental rate (R) with after tax $\mathrm{MP}_{\mathrm{K}}$ and using Ramsey savings rule as in Barro we get

$$
\begin{gathered}
g_{\mathrm{k}}=g_{y}=g_{c}=\frac{1}{\theta}\left\{(1-r) \alpha A^{\frac{1}{\alpha}} \lambda^{\frac{\beta}{\alpha}}\right. \\
\left.(1-\lambda)^{\frac{1-\alpha-\beta}{\alpha}}[(1-\psi) r]^{\frac{1-\alpha}{\alpha}} L^{\frac{\beta}{\alpha}}-\rho\right\}
\end{gathered}
$$

in a steady state growth.
The equation (15) has important implications. As the growth rate incorporates element of corruption and allocation of fund for distributive politics, the growth rate becomes lower in (15) as compared to (9). Given the values of $r$ and $\psi$ and the parameters of the system whether the diversion of fund from distributive policies to long term investment will enhance growth depend on the value of $\lambda$ and the production elasticities of $K$ and $\mathrm{G}_{1}$ and $\mathrm{G}_{2}$.

Differentiating (15) w.r.t. $\lambda$ we get,

$$
\frac{\partial g_{y}}{\partial \lambda} \stackrel{>}{=} \quad \text { if } \quad \lambda \stackrel{<}{=} \frac{\beta}{1-\alpha}
$$

By our assumption on production function

$\beta>1-\alpha-\beta$ i.e., $\frac{\beta}{1-\alpha}>\frac{1}{2}$.

It implies that increase in $\lambda$ will lead to higher growth if $\lambda\left\langle\frac{\beta}{1-\alpha}\right\rangle \frac{1}{2}$. The growth rate is maximum if $\lambda=\frac{\beta}{1-\alpha}$. If maximization of growth is the objective, the available fund will be allocated between $G_{1}$ and $G_{2}$ till the marginal products of $G_{1}$ and $G_{2}$ are equal and from that equality, it follows, $\frac{G_{1}}{G_{2}}=\frac{\beta}{1-\alpha-\beta}>1$ (by our assumption $\beta>1-\alpha-\beta$ ). Then it is consistent with $\lambda=\frac{\beta}{1-\beta}>\frac{1}{2}$. That means, for maximization of growth, it requires $\lambda>\frac{1}{2}$.

If it is a selfish government and its objective is maximization of political gain it may choose a value of $\lambda$ less than $\frac{\beta}{1-\alpha}$. Tax rate $(r)$ is another determinant of growth rate. In Barro and Sala-i-Martin, the benevolent government fixes tax rate at $r=1-\alpha$ to maximize growth. Here, in the modified model, in order to maximize growth rate, we differentiate equation (15) w.r.t. $r$ and set it equal to zero i.e. $\frac{\partial g_{y}}{\partial r}=0$. After simplification we get $r=1-\alpha$. That means, optimal tax rate is equal to the sum of production elasticities of $\mathrm{G}_{1}$ and $\mathrm{G}_{2}$ i.e. $\beta+(1-\alpha-\beta)=1-\alpha$. It implies that growth maximizing tax rate remains the same as in the original model even when tax revenue is spent on two different heads 
and their production elasticities are different. However, if the objective of the government is maximization of political gain, the value of $r$ may be different from $(1-\alpha)$.

\section{DETERMINATION OF OPTIMAL TAX RATE AND COMPOSITION OF PUBLIC EXPENDITURES IN AN ENDOGENOUS FRAMEWORK}

In the last section we have determined the growth rate assuming the tax rate and share of public expenditures as given and constant over time. Ghosh \& Gregoriou (2008), in an extension of the model by Devarajan et al. (1996), have constructed a model to determine optimal tax rate and optimal shares of capital and current expenditures in an endogenous framework to maximize growth. In Ghosh \& Gregoriou, the welfare maximizing fiscal policy of the benevolent government (the secondbest outcome) optimally chooses the fiscal instruments to maximize the representative agent's utility taking the private individual's choices in a decentralized framework as a given constraint. The authors have considered a CES production technology with two types of government spending as in Devarajan et al. (1996):

$$
y=\left[\alpha k^{-\varepsilon}+\beta g_{1}^{-\varepsilon}+\gamma g_{2}^{-\varepsilon}\right]-\frac{1}{\varepsilon}
$$

where $\quad \alpha+\beta+\gamma=1, \varepsilon \geq-1$

The government budget constraint is:

$$
g_{1}+g_{2}=\tau y \text { where } \tau \text { is the tax rate. }
$$

The preference of the representative agent is represented by constant elasticity of substitution in lifetime utility as

$U=\int_{0}^{\infty}\left(\frac{C^{1-\delta}-1}{1-\delta}\right) e^{-\rho t} d t$ where utility is derived from private consumption.

The share of government expenditures are:

$$
g_{1}=\phi \tau y \quad \text { and } g_{2}=(1-\phi) \tau y
$$

The agent's budget constraint is:

$$
\dot{k}=(1-\tau) y-C
$$

The representative agent maximizes ' $U$ ' optimally choosing $\mathrm{C}$ and $\dot{k}$ and derives the growth path as

$$
\lambda=\frac{\dot{C}}{C}=(1-\tau) \frac{\partial y}{\partial k}-\rho
$$

The benevolent government optimally determines $\tau, g_{1}, g_{2}$ to maximize growth taking (16) and other constraints as given and the optimal values of $\tau, \phi$ and $(1-\phi)$ are determined in terms of technological and behavioral parameters. The implication of this result is that here also the values of the tax rate and expenditure shares are constant as in the last section although they are determined endogenously. The growth rate is also determined in terms of parameters and whether a change in the composition of public expenditures will lead to a change in the growth rate will depend on these parameters.

\section{DETERMINATION OF FISCAL VARIABLES FOR MAXIMIZATION OF POLITICAL GAIN}

We have so far discussed how the optimal tax rate and composition of public expenditures are determined by a benevolent government and examined their impact on economic growth. Now we like to see how fiscal variables are determined by a government whose objective is to maximize political gain to retain power by manipulating fiscal instruments. As before, the two types of government expenditures are denoted by $\mathrm{G}_{1}$ and $\mathrm{G}_{2}$ respectively and balanced budget fiscal system is assumed. Therefore, $G_{1}+G_{2}=T=r . Y$ where $Y$ is income, $r$ is tax rate and $T$ is total tax revenue. $\lambda$ is the share of tax revenue allocated to $G_{1}$ and $(1-\lambda)$ is the share of $G_{2}$. So, here we have

$$
G_{1}=\lambda r Y, \quad G_{2}=(1-\lambda) r Y
$$

In a low income multi-party democracy, the government is basically concerned with its short-term gain and the political parties are not very different from each other in respect of their objectives and economic programs. The private agents derive utility from private 
consumption $(\mathrm{C})$ and distributive expenses $\left(G_{2}\right)$ in a non-separable form. Both $G_{1}$ and $G_{2}$ affect the utility of the individuals through production. Since $G_{2}$ involves many populist and distributive measures and the scope of rent seeking is there, the party in power can derive some political mileage from $G_{2}$. So, the government as an optimizing agent manipulates the fiscal instruments to maximize its total political gain, which includes both private utility as well as self-interest of the government. Naturally, the government may allocate more funds to $G_{2}$ despite the realization that it may adversely affect economic growth. Following Agenor (2008), we consider a non-separable utility function in $C$ and $G_{2}$ for the private agent as $U=\frac{\left(C G_{2}^{\varphi}\right)^{1-\theta}}{1-\theta}$ where $\theta=\frac{1}{\sigma}$ is the reciprocal of the inter-temporal elasticity of substitution in utility and $\varphi>0$ is the measure of value assigned to the contribution of $G_{2}$ in private utility. To ensure concavity property of the function, the restrictions imposed are: $\varphi(1-\theta)<1$ and $(1+\varphi)(1-\theta)<1$.

As in Chen (2005), the utility function could be written in Cobb-Douglas form also:

$$
U=\left\lfloor\left(C^{\alpha} G_{2}^{1-\alpha}\right)^{1-\theta}-1\right\rfloor / 1-\theta
$$

Since $\mathrm{G}_{2}$ generates some electoral benefits to the government apart from contributing to the private utility, an additional term is introduced into the objective function in Agenor (2008) to capture this political gain in the decision-making.

The self interest of the government from $G_{2}$ can be expressed as

$$
\Phi=\eta G_{2}^{\mu}
$$

where $\Phi$ is the political gain, $\mu$ is the measure of value assigned to the contribution of $\mathrm{G}_{2}$ in political gain and $\eta$ is the parameter reflecting the capacity of the government to reap the political mileage from $G_{2}$. Here, $\eta>0,0<\mu<1$. is:

The production technology in Cobb-Douglas form

$$
Y=A K^{\alpha} G_{1}^{\beta}\left(L G_{2}\right)^{1-\alpha-\beta}
$$

It can be expressed as

$$
Y=\bar{A} K \lambda^{\beta / \alpha}(1-\lambda)^{\frac{1-\alpha-\beta}{\alpha}} \cdot r^{\frac{1-\alpha}{\alpha}} \text { where }
$$

$\bar{A}=A^{\frac{1}{\alpha}} L^{\frac{1-\alpha-\beta}{\alpha}}$ and $L$ is constant.

Similarly, $G_{2}$ can be expressed as

$$
G_{2}=r^{\frac{1}{\alpha}} \bar{A} K \lambda^{\beta / \alpha}(1-\lambda)^{\frac{1-\alpha-\beta}{\alpha}}
$$

The budget of the economy is:

$$
Y=C+\dot{K}+G_{1}+G_{2} \text { or } \quad \dot{K}=(1-r) Y-C
$$

Given the values of $r, \lambda$ and other parameters, the representative private agent maximizes

(20) $\mathrm{V}=\int_{0}^{T}\left\{\frac{\left(C G_{2}^{\varphi}\right)^{1-\theta}}{1-\theta}\right\} e^{-\rho t} \cdot d t$ s.t. $\dot{K}=(1-r) Y-C$.

It is a definite period optimization problem. In Agenor (2008) the private agent solves the problem by optimally choosing $C$ and gets the growth path for consumption in a decentralized framework as

$$
\text { (21) } \frac{\dot{C}}{C}=-\sigma\left(\frac{\dot{v}}{v}\right)+\gamma\left(\frac{\dot{G}_{2}}{G_{2}}\right) \text { where } \gamma=\sigma \varphi\left(1-\frac{1}{\sigma}\right)
$$

and $v$ is present value shadow price of $K$. After solution and simplification, the growth path is expressed in terms of the parameters as

$$
\begin{gathered}
\frac{\dot{C}}{C}=-\left(\frac{\sigma}{1-\gamma}\right)\{\rho-(1-r)(1-\alpha-\beta)\} \\
{\left[r^{\frac{1-\alpha}{\alpha}} \lambda^{\frac{\beta(1-\alpha)}{\alpha}}(1-\lambda)^{\frac{1-\alpha-\beta(1-\alpha)}{\alpha}}\right]}
\end{gathered}
$$

The growth rate of consumption depends on the given values of $r, \lambda$ and the parameters.

In the modification of the model, we incorporate the self interest of the government from $\mathrm{G}_{2}$ into the political gain function. Now the objective of the government becomes

(22) $\mathrm{Max} \mathrm{W}=\int_{0}^{T}\left[\frac{\left(C G_{2}{ }^{\varphi}\right)^{1-\theta}}{1-\theta}+\eta G_{2}^{\mu}\right] e^{-\rho t} d t$ 
s.t. (19), (21) and other constraints. This will be solved by optimally choosing $r$ and $\lambda$ subject to the constraints.

For solution of the dynamic optimization problem in (22), the current - value Hamiltonian is:

(23) $H=\frac{\left(C G_{2}^{\varphi}\right)^{1-\theta}}{1-\theta}+\eta G_{2}^{\mu}+v[(1-r) Y-C]$

Here, $\mathrm{Y}, \mathrm{G}_{1}$ and $\mathrm{G}_{2}$ depend on $r$ and $\lambda$ which will be optimally determined by the government in terms of parameters [see (17), (18)]. That means, the control variables are $r$ and $\lambda$.

The F.O.C.s $\frac{\partial H}{\partial r}=0, \frac{\partial H}{\partial \lambda}=0$ will give the optimum value of $r$ and $\lambda$ at each point of time. They will be determined in terms of the state variable $K$, costate variable $v$ and set of parameters at each point of time. Two new parameters $\mu$ and $\eta$ enter into the parameter set of the modified model. It is assumed that S.O.C. is satisfied.

Now, $\dot{K}$ and $\dot{v}$ along with transversality conditions will trace out the paths for dynamic solution to this problem. Along the optimal path the control variables $r$ and $\lambda$ are determined in terms of parameters and time only. The set of parameters is : $\{\alpha, \beta, \theta, \varphi, \mu, \eta, \rho\}$.

The dynamic solution of this problem is given by the following two differential equations along with the initial and transversality conditions:

$$
\begin{aligned}
& \dot{K}=(1-r)\left\{\bar{A} K \lambda^{\beta / \alpha}(1-\lambda)^{\frac{1-\alpha-\beta}{\alpha}} r^{\frac{1-\alpha}{\alpha}}\right\}-C \\
& \dot{v}=-\frac{\partial H}{\partial K}+\rho v
\end{aligned}
$$

Assuming further that the solution is convergent and dynamically stable, the growth rate of $\mathrm{K}$ can be expressed as

$$
\frac{\dot{K}}{K}=(1-r)\left\{\bar{A} \lambda^{\beta / \alpha}(1-\lambda)^{\frac{1-\alpha-\beta}{\alpha}} r^{\frac{1-\alpha}{\alpha}}\right\}-\frac{C}{K}
$$

In steady state, all the variables grow at constant rates. Therefore, growth rate is $g=\frac{\dot{C}}{C}=\frac{\dot{K}}{K}=\frac{\dot{Y}}{Y}$. That means, $\left(\frac{C}{K}\right)$ is constant in the long-run and growth rate is also constant. The growth rate is determined in terms of the parameters. The range of values of $\mu$ and $\eta$ and their impact on the growth are of special interest in this paper. So, we like to see what happens to the growth rate and convergent values of $\mathrm{K}$ in (26) and (24) if changes occur in the values of $\mu$ and $\eta$. A closed-form solution of the differential equation in (24) is difficult to find out. Again, the values of $\mu$ and $\eta$ cannot be easily estimated from the empirical data. So, we can run a simulation in (24) and (26) to get some idea about the effect of $\mu$ and $\eta$ on the growth rate. If the values of $\eta$ and $\mu$ are such that political gain from $G_{2}$ is very high, then the government may decide to allocate a greater share of the fund to distributive policies undermining growth.

\section{EFFECT OF CHANGE OF VALUES OF $\mu$ AND $\eta$ ON THE GROWTH RATE AND STEADY STATE VALUE OF K: A SIMULATION}

The entire simulation has been done by MATLAB software. The differential equation in (24) has been solved by the numerical method known as 'Runga Kutta method'. lows:

The given values and simulation results are as fol$\alpha=0.2, \beta=0.5, \varphi=0.2, \mu=0.2, \eta=0.25, \bar{A}=100$,
$\mathrm{K}(0)=10000, \mathrm{C} / \mathrm{K}=2, \mathrm{r}=0.25, \lambda=\mu+\eta$ 
Section A: $\quad$ Result of change of $\mu$ and $\eta$ on convergent $\mathrm{K}$ via $\lambda$

$\mathrm{K}$ converges at

37.1837 [at $\mu=0.1] \quad \dot{K} / K=$
$9.7109 \quad$ [at $\mu=0.15]$
$2.793 \quad$ [at $\mu=0.20]$
$0.970 \quad$ at $\mu=0.25]$
$0.4451 \quad$ [at $\mu=0.3]$
$0.2924 \quad$ [at $\mu=0.4]$

$\mathrm{Dk} / \mathrm{k}-1.9889$

Dk/k - 1.9862

$\mathrm{Dk} / \mathrm{k}-1.9838$

$\mathrm{Dk} / \mathrm{k}-1.9817$

$\mathrm{Dk} / \mathrm{k}-1.9802$

$\mathrm{Dk} / \mathrm{k}-1.9793$

With $\mu=0.2$

K converges at
37.18 at $\eta=0.25] \dot{K} / K=$
$\mathrm{Dk} / \mathrm{k}=1.9889$
9.7109 [at $\eta=0.3$ ]
$\mathrm{Dk} / \mathrm{k}=1.9817$
0.2918 [at $\eta=0.4$ ]
$\mathrm{Dk} / \mathrm{k}=1.9793$
0.4695 [at $\eta=0.5]$
$\mathrm{Dk} / \mathrm{k}=1.9803$

Section B: $\quad$ Result of change of $\mu$ and $\eta$ on convergent $\mathrm{K}$ via $r$

$\lambda=0.4, r=\eta-\mu$

$\mathrm{K}$ converges at

23.8619 [at $\mu=0.1, \eta=0.31,] \dot{K} / K=$

$\mathrm{Dk} / \mathrm{k}=1.994$

$68.95 \quad[$ at $\mu=0.11]$

$\mathrm{Dk} / \mathrm{k}=1.995$

173.0791 at $\mu=0.12]$

$\mathrm{Dk} / \mathrm{k}=1.994$

$\mathrm{K}$ converges at

7.0879 [at $\eta=0.31, \mu=0.1] \dot{K} / K=$
1.7858 [at $\eta=0.32$ ]
0.3771 [at $\eta=0.33$ ]
0.0659 [at $\eta=0.34$ ]
0.0094 [at $\eta=0.35$ ]

$\mathrm{Dk} / \mathrm{k}=1.9928$

$\mathrm{Dk} / \mathrm{k}=1.9914$

$\mathrm{Dk} / \mathrm{k}=1.9899$

$\mathrm{Dk} / \mathrm{k}=1.9881$

$\mathrm{Dk} / \mathrm{k}=1.9862$

Section C: $\quad$ Effect of change of value of $\mu$ and $\eta$ on the $\dot{K} / K$ via $\lambda$ and $r$

$\lambda=\eta+\mu, r=\eta-\mu$.

$\mathrm{K}$ converges at

$$
\begin{aligned}
& 23.8618 \text { [at } \eta=0.3, \mu=0.1] \dot{K} / K \\
& 5.40664 \text { [at } \eta=0.31, \mu=0.1] \\
& 0.94244 \text { [at } \eta=0.32, \mu=0.1] \\
& 0.12289 \text { [at } \eta=0.33, \mu=0.1] \\
& 0.01165 \text { [at } \eta=0.34, \mu=0.1]
\end{aligned}
$$$$
\mathrm{Dk} / \mathrm{k}=1.994
$$$$
\mathrm{Dk} / \mathrm{k}=1.9925
$$$$
\mathrm{Dk} / \mathrm{k}=1.9908
$$$$
\mathrm{Dk} / \mathrm{k}=1.9888
$$

$\mathrm{Dk} / \mathrm{k}=1.986$ 

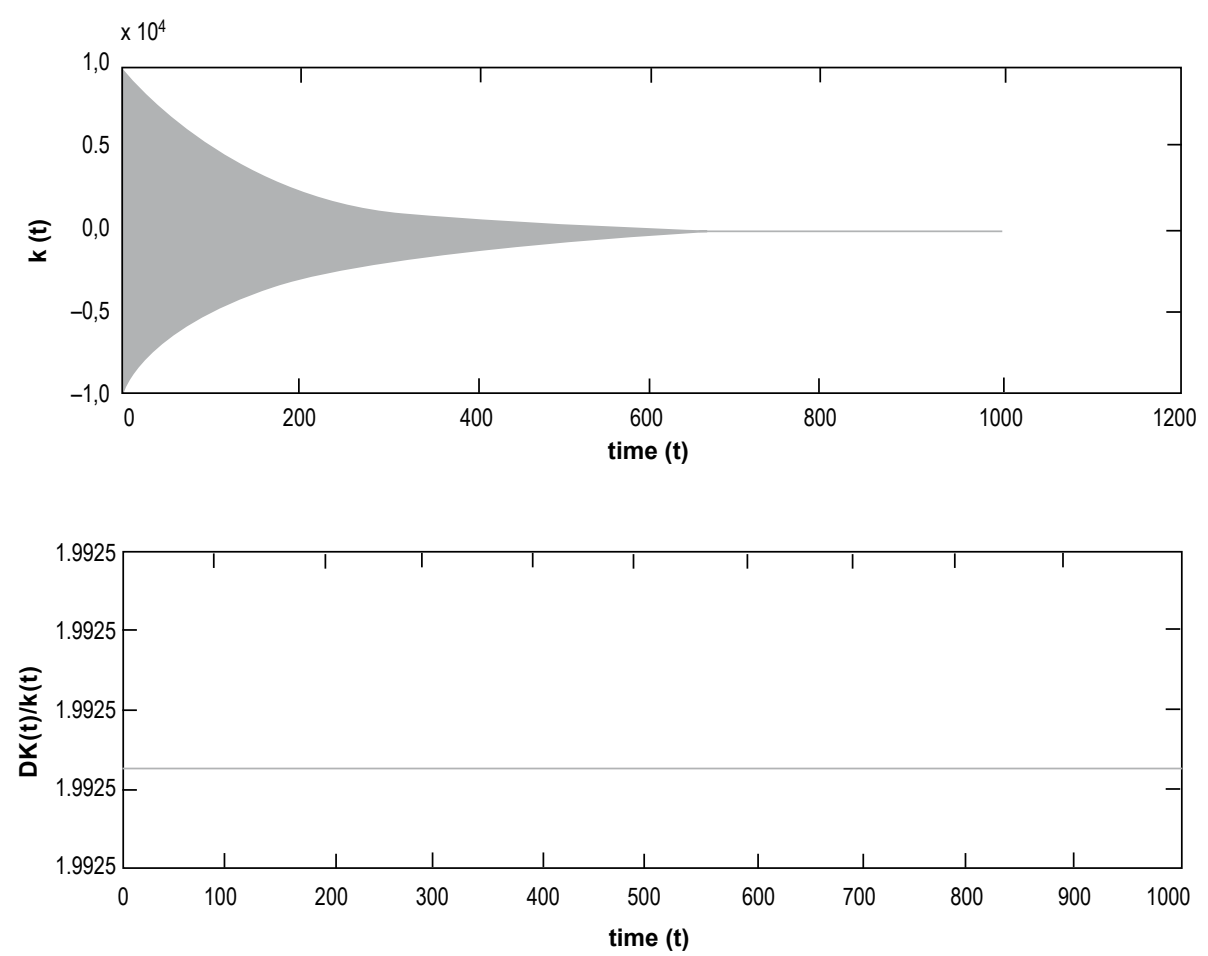

Figure 1. Convergence of $\mathrm{K}(t)$ and $\frac{\dot{K}}{K}$ to steady state values.

Note. $\mathrm{K}(t)$ converges at 5.4066 and $K / K$ converges at 1.9925 with $\mu=0.1$ and $\eta=0.31$.

The results show that both $\mathrm{K}$ and $\dot{K} / K$ converge to steady state values within the following range of values of the parameters: $\alpha \leq 0.2, \mu=0.10-0.12$ and $\eta=$ $0.31-0.35$. One such convergent value is shown in Figure 1 . The convergent value of $\mathrm{K}$ and $\dot{K} / K$ decline, while $\mu$ and $\eta$ rises almost in all cases. That means that growth rate declines at a steady rate as $\mu$ and $\eta$ rises. However, the effect of change of $\mu$ on convergent $\mathrm{K}$ via $r$ in section $\mathrm{B}$ gives a different result. It is found that convergent value rises with $\mu$ and $(\dot{K} / K)$ has oscillation. In section $\mathrm{A}, \mathrm{K}$ is convergent and growth rate is stable within the range of values of $\eta$ of 0.25 to 0.4 . Since closed-form solution is not obtained, $\lambda$ and $r$ have been expressed in terms of some linear combination of $\mu$ and $\eta$. It is interesting to note that in section $C$, both convergent value of $\mathrm{K}$ and growth rate of $\mathrm{K}$ decline as $\eta$ rises and its effect is reflected through $\lambda$ and $r$.
The basic proposition of this study is that if the government derives more political mileage from distributive programs vis-à-vis investment for long term growth, it will be inclined to allocate more funds to distributive expenses adversely affecting economic growth. The simulation results are on the whole consistent with this proposition.

The effect $\mu$ and $\eta$ on growth via $\lambda$, which is our prime query, and the simulation results are quite consistent with our theoretical proposition. The effect of increase of $\eta$ on growth rate via $r$ is also clear. But the effect of $\mu$ on growth through $r$ is somewhat different. The intuitive explanation may be that the effect of a change in $\lambda$ on growth is more direct given the production elasticities of $G_{1}$ and $G_{2}$, whereas the effect of $r$ on growth is not so straightforward. In our 
present situation, production elasticity of $\mathrm{G}_{2}$ is greater than that of K. Now, given the value of $\lambda$, increase in $r$ following an increase in $\mu$ may lead to changes in $\mathrm{K}$ and $\mathrm{Y}$. In our CRS model, as $(1-\alpha-\beta)>\alpha$, increase in $r$ with increase in $\mu$ may result in higher growth rate.

Table 1.

Percentage Share of Revenue Expenditure (RE) and Capital Expenditure $(C E)$ in the Total Expenditure of the Central Government of India over time

\begin{tabular}{|c|c|c|c|}
\hline Year & $\%$ Share of RE & $\%$ Share of CE & $\mathrm{RE} / \mathrm{CE}$ \\
\hline $1971-72$ & 57 & 43 & 1.32 \\
\hline $1972-73$ & 57 & 43 & 1.32 \\
\hline $1973-74$ & 58 & 42 & 1.38 \\
\hline $1974-75$ & 57 & 43 & 1.32 \\
\hline $1975-76$ & 56 & 44 & 1.27 \\
\hline $1976-77$ & 60 & 40 & 1.50 \\
\hline $1977-78$ & 58 & 42 & 1.38 \\
\hline $1978-79$ & 56 & 44 & 1.47 \\
\hline $1979-80$ & 62 & 38 & 1.63 \\
\hline $1980-81$ & 63 & 37 & 1.70 \\
\hline $1981-82$ & 60 & 40 & 1.50 \\
\hline $1982-83$ & 60 & 40 & 1.50 \\
\hline $1983-84$ & 62 & 38 & 1.63 \\
\hline $1984-85$ & 63 & 37 & 1.70 \\
\hline $1985-86$ & 64 & 36 & 1.77 \\
\hline $1986-87$ & 64 & 36 & 1.77 \\
\hline $1987-88$ & 67 & 33 & 2.00 \\
\hline $1988-89$ & 68 & 32 & 2.12 \\
\hline $1989-90$ & 69 & 31 & 2.22 \\
\hline $1990-91$ & 69 & 31 & 2.22 \\
\hline $1991-92$ & 73 & 27 & 2.70 \\
\hline $1992-93$ & 75 & 25 & 3.00 \\
\hline 1993-94 & 76 & 24 & 3.16 \\
\hline 1994-95 & 75 & 25 & 3.00 \\
\hline $1995-96$ & 78 & 22 & 3.54 \\
\hline $1996-97$ & 79 & 21 & 3.76 \\
\hline $1997-98$ & 77 & 23 & 3.34 \\
\hline 1998-99 & 77 & 23 & 3.34 \\
\hline $1999-00$ & 83 & 17 & 4.88 \\
\hline $2000-01$ & 85 & 15 & 5.66 \\
\hline 2001-02 & 83 & 17 & 4.88 \\
\hline $2002-03$ & 81 & 19 & 4.26 \\
\hline 2003-04 & 76 & 24 & 3.16 \\
\hline 2004-05 & 77 & 23 & 3.34 \\
\hline $2005-06$ & 86 & 14 & 6.14 \\
\hline 2006-07 & 88 & 12 & 7.33 \\
\hline $2007-08$ & 83 & 17 & 4.88 \\
\hline 2008-09 & 89 & 11 & 8.00 \\
\hline 2009-10 & 88 & 12 & 7.33 \\
\hline
\end{tabular}

Source: Handbook of Statistics on Indian Economy, Reserve Bank of India, 2010-11. 
Table 2.

Expenditure on Major Heads in Union Budget 2010 - 11, Government of India (Rupees Crore at current price)

\begin{tabular}{lll} 
Total expenditure & - & $11,08,749$ \\
Non-plan expenditure & - & $7,35,657$ \\
Plan expenditure & - & $3,73,092$ \\
\multicolumn{2}{c}{ Major heads of Plan expenditure } \\
a) Infrastructure & - & $1,37,674$ \\
b) Education & - & 31,036 \\
c) Health & - & 22,300 \\
\hline
\end{tabular}

Source: Ministry of Finance, Government of India.

The nature of government expenditure in India exhibits important features for our purpose. Table 1 shows that the share of revenue expenditure in the total budget is not only high compared to capital expenditure but also it has increased over time. In Table 2 we find that $66 \%$ of the annual budget has been earmarked for nonplan expenditure whereas infrastructure, education and health, which are important heads of plan expenditure, have received only $12 \%, 2.7 \%$ and $2 \%$ respectively. The revenue expenditure includes current expenses like salaries, pension, allowances, subsidies, interest payment and maintenance. That means that the government in India is spending more on distributive programs.
It is also evident from Table 3 that large shares of both revenue and capital expenditures are spent on defense, interest payment on public borrowing and subsidies. This section is just a statement of the nature of government spending in a developing country with democratic set up. Whether such spending is motivated by political interest or how economic growth is affected by such spending can not be ascertained from this information. To establish a relationship between our theoretical proposition and Indian data we need rigorous econometric analysis of the data which we have not done in this paper. However, in further extension of this work, it is possible to verify empirically the relationship between the nature of government spending, political interest and economic growth using Indian data. In that case we have to estimate the production elasticities of various components of public expenditure and see which component of the expenditures is more productive. It is also necessary to check whether the government is politically benefited from distributive policies. Therefore, here we are not in a position to conclude that the government in India is allocating more funds on less productive heads and neglecting growth due to political reasons. 
Table 3

Major Heads of Revenue Expenditure (RE) and Capital Expenditure (CE) of the Government of India over time

\begin{tabular}{|c|c|c|c|c|c|}
\hline Year & $\begin{array}{c}\text { Defense Expenditure } \\
\text { as } \% \text { of RE }\end{array}$ & $\begin{array}{c}\text { Interest Payment on } \\
\text { Loan as } \% \text { of RE }\end{array}$ & $\begin{array}{l}\text { Subsidy as \% } \\
\text { of RE }\end{array}$ & $\begin{array}{c}\text { Loan \& Advances } \\
\text { as \% CE }\end{array}$ & $\begin{array}{c}\text { Defense Expenditure as } \\
\% \text { of } \mathrm{CE}\end{array}$ \\
\hline $1970-71$ & 33.61 & 19.36 & 3.00 & 62.23 & 5.93 \\
\hline $1971-72$ & 33.95 & 16.89 & 2.62 & 61.80 & 6.12 \\
\hline $1972-73$ & 31.71 & 17.10 & 4.52 & 70.62 & 6.42 \\
\hline $1973-74$ & 31.00 & 18.46 & 7.56 & 70.68 & 5.81 \\
\hline $1974-75$ & 33.82 & 17.63 & 7.38 & 61.73 & 4.51 \\
\hline $1975-76$ & 32.26 & 17.60 & 6.74 & 58.34 & 4.09 \\
\hline $1976-77$ & 28.38 & 17.99 & 11.45 & 65.29 & 3.99 \\
\hline $1977-78$ & 26.20 & 18.07 & 14.13 & 64.94 & 3.88 \\
\hline $1978-79$ & 24.47 & 18.57 & 13.81 & 70.09 & 3.14 \\
\hline $1979-80$ & 26.21 & 19.42 & 15.43 & 65.93 & 3.66 \\
\hline $1980-81$ & 22.75 & 18.07 & 14.07 & 63.23 & 3.90 \\
\hline $1981-82$ & 24.95 & 20.74 & 12.60 & 57.40 & 4.92 \\
\hline $1982-83$ & 23.98 & 21.01 & 12.07 & 61.28 & 4.37 \\
\hline $1983-84$ & 23.32 & 21.55 & 13.04 & 60.63 & 4.83 \\
\hline $1984-85$ & 22.84 & 21.57 & 14.58 & 57.68 & 4.62 \\
\hline $1985-86$ & 20.70 & 22.14 & 14.14 & 59.16 & 5.16 \\
\hline $1986-87$ & 22.46 & 22.63 & 13.34 & 58.02 & 5.89 \\
\hline $1987-88$ & 19.19 & 24.37 & 12.95 & 57.92 & 14.07 \\
\hline $1988-89$ & 17.67 & 26.39 & 14.29 & 58.99 & 15.13 \\
\hline $1989-90$ & 15.88 & 27.65 & 16.31 & 58.85 & 14.71 \\
\hline 1990-91 & 14.79 & 29.24 & 16.54 & 61.83 & 14.32 \\
\hline $1991-92$ & 13.90 & 32.32 & 14.89 & 60.86 & 16.84 \\
\hline $1992-93$ & 13.06 & 33.52 & 11.68 & 54.48 & 18.29 \\
\hline $1993-94$ & 13.85 & 33.97 & 10.73 & 60.72 & 20.39 \\
\hline 1994-95 & 13.45 & 36.08 & 9.71 & 61.45 & 17.65 \\
\hline $1995-96$ & 13.47 & 35.78 & 9.05 & 63.30 & 20.86 \\
\hline $1996-97$ & 13.21 & 37.42 & 9.75 & 66.26 & 20.22 \\
\hline $1997-98$ & 14.51 & 36.40 & 10.28 & 66.11 & 17.60 \\
\hline 1998-99 & 13.80 & 35.98 & 10.90 & 70.03 & 15.96 \\
\hline 1999-00 & 14.14 & 36.23 & 9.83 & 50.92 & 24.21 \\
\hline 2000-01 & 13.40 & 35.75 & 9.66 & 50.90 & 25.93 \\
\hline 2001-02 & 12.62 & 35.65 & 10.35 & 56.35 & 26.64 \\
\hline $2002-03$ & 11.99 & 34.69 & 12.81 & 42.49 & 20.06 \\
\hline 2003-04 & 11.96 & 34.32 & 12.32 & 25.58 & 15.18 \\
\hline 2004-05 & 11.29 & 33.59 & 11.29 & 34.24 & 36.26 \\
\hline $2005-06$ & 10.97 & 30.18 & 10.81 & 17.08 & 48.72 \\
\hline 2006-07 & 10.04 & 29.20 & 11.10 & 12.39 & 49.18 \\
\hline 2007-08 & 9.12 & 28.77 & 11.93 & 9.55 & 31.68 \\
\hline 2008-09 & 9.23 & 24.21 & 16.34 & 15.64 & 45.38 \\
\hline 2009-10 & 9.75 & 24.21 & 14.45 & 13.75 & 41.51 \\
\hline
\end{tabular}

Source: Handbook of Statistics on Indian Economy, Reserve Bank of India, 2010-11. 


\section{CONCLUSIONS AND SUMMARY RESULTS}

A rich literature is available to explain the determination of optimal tax rate and composition of public expenditure for maximization of economic growth. But the government in a democratic setup of the developing world is not always guided by the objective of maximization of growth. Instead, it may manipulate fiscal instruments to capitalize on its political gain so that it can retain power. Both the government and voters in such countries are generally selfish and myopic in the sense that the voters prefer to get direct and immediate benefits from the government. The government also adopts short term populist measures and resorts to distributive politics in order to strengthen its support base undermining long term growth. Not only the poor, the well-off groups of the society, including the business clusters, farmers' lobbies, government employees and other interest groups, also try to derive immediate benefits from the government in the forms of subsidies, salaries, allowances and concessions. In effect, long term growth suffers.

In this paper we have analyzed the fiscal behavior of the government in a low income democracy with respect to the nature of public spending and its impact on economic growth from a different angle. We used the structure of the existing theoretical models and made modifications therein to derive new results. Unlike the benevolent government, here the government is assumed to maximize its political interest by optimally choosing the fiscal instruments. The optimal tax rate and public expenditure shares are determined in terms of technological and behavioral parameters in an endogenous framework. The Barro Model has been extended to incorporate two types of government spending: (i) investment for long term growth $\left(G_{1}\right)$, and (ii) expenditure on distributive policies $\left(\mathrm{G}_{2}\right)$. $\mathrm{G}_{2}$ has been assumed to be less productive than $G_{1}$. The result shows that allocation of more funds to $\mathrm{G}_{2}$ lowers economic growth. The model of Agenor (2008) has been modified to incorporate political gain from $\mathrm{G}_{2}$. $\mathrm{G}_{2}$ enters into the utility function of the households in non-separable form with private consumption. It also enters into production function and political gain function of the government in the modified model. Two new parameters $\mu$ and $\eta$ that capture the political gain from $\mathrm{G}_{2}$ has been introduced into the model. Here also, fiscal variables and growth rate are determined in terms of parameters. The theoretical result proposes that if political gain from $\mathrm{G}_{2}$ is higher, the government will be inclined to allocate more funds to distributive policies and this affects economic growth adversely. A simulation has been done to examine the effect of the two new parameters $\mu$ and $\eta$; it has been found that if $\mu$ and $\eta$ rise, steady state growth rate declines.

Some examples have been cited from the Indian situation with respect to the nature of government spending in the country and it is found that the government spends more on revenue expenditure compared to capital expenditure. Not only that the share of revenue expenditure has increased over time and, even within revenue expenditure, major expenses have been done on defense, interest payment and subsidy. No econometric exercise has been done with respect to the relationship between the nature of government spending and growth rate of GNP.

Naturally, this paper could not ascertain empirically whether such spending is due to political compulsions or if there is any relationship between nature of government spending and economic growth. However, in further research, rigorous econometric analysis can be done to verify this relationship. 


\section{References}

Agenor, P. R. (2008). Fiscal Policy and Endogenous Growth with Public Infrastructure, Oxford Economic Papers, $60,57-87$

Alesina, A., \& Rodrick, D. (1994). Redistributive Politics and Economic Growth. Quarterly Journal of Economics, $109,465-90$.

Banerjee, A. V., \& Newman, A. F. (1993). Occupational Choice and the Process of Development. Journal of Political Economy, 101(2), 274 - 98.

Barro, R. J. (1990). Government Spending in a Simple Model of Endogenous Growth. Journal of Political Economy, 98(October) S103 - S125.

Barro, R. J., \& Becker, G. S. (1989). Fertility Choice in a Model of Economic Growth. Econometrica, 57(March), $481-501$.

Barro, R. J., \& Sala-i-Martin, X. (1995). Economic Growth. Boston: McGraw Hill.

Chen, B. L. (2006). Economic Growth with an Optimal Public Spending Composition. Oxford Economic Papers, 58, 123 - 36.

Devarajan, S., Swaroop, V., \& Zou, H. (1996). The Composition of Public Expenditure and Economic Growth. Journal of Monetary Economics, 37, 313 - 344.

Galor, O., \& Zeira, J. (1993). Income Distribution and Macroeconomics. Review of Economic Studies, $60(1), 35-52$.

Ghosh, S., \& Gregoriou, A. (2008). The Composition of Government Spending and Growth: Is Current or Capital Spending Better? Oxford Economic Papers, $60,484-516$

Grossman, G. M. \& Helpman, E. (1991). Innovation and Growth in the Global Economy. Cambridge, MA: MIT Press.

Handbook of Statistics on Indian Economy. Reserve Bank of India, 2010-11.

Marjit, S., Kolmar, M., \& Mukherjee, V. (2001). Redistributive Politics, Corruption and Quality of Public Investment. Paper presented at the Fiscal Affairs Division, IMF.

Marjit, S., \& Maity, D. (2006). Politics and Contemporary Macroeconomy of India. In India Macroeconomics
Annual, Centre for Studies in Social Sciences (pp. 9-55). India: Sage Publications Ltd.

Marjit, S., Mukherjee, V., \& Kolmar, M. (2006) Poverty, Taxation and Governance. Journal of International Trade \& Economic Development, 15(3), 325 - 333.

Meltzer, A. H., \& Richard, S. F. (1981). A Rational Theory of the Size of the Government. Journal of Political Economy, 89(51), $914-27$.

Persson, T., \& Tabellini, G. (1994). Is Inequality Harmful for Growth?. American Economic Review, 84(3), $600-621$

Ramsey, F. (1928). A Mathematical Theory of Saving. Economic Journal, 38(December), 543 - 559.

Rebelo, S. (1991). Long-run Policy Analysis and Long-run Growth. Journal of Political Economy, 99(June), $500-521$

Romer, P. M. (1986). Increasing Returns and Long-run Growth. Journal of Political Economy, 94(October), $1002-1037$.

Romer, P. M. (1990). Endogenous Technological Change. Journal of Political Economy, 94(October), S71 S102.

Sarkar, A. (2006). Political Economy of West Bengal: A Puzzle and a Hypothesis. Economic and Political Weekly, 61(4), $341-48$.

Sasmal, J. (2002). Size of Government, Nature of Government Spending and Level of Corruption in a Low Income Country: A Static Partial Equilibrium Analysis. Artha Beekshan, 11(3), 12 - 21

Sasmal, J. (2004). Endogenous Growth with Government Spending - Effects of Size of Government, Distributive Politics and Corruption with Special Reference to Low Income Countries. Paper presented at the Annual Conference of the Dept. of Economics, Jadavpur University, India.

Sasmal, J. (2007). Size of Government, Distributive Politics and Governance : A Simple Political Choice Model. Proceedings of the $90^{\text {th }}$ Annual Conference Volume, Indian Economic Association, 1240 - 1246.

Uzawa,H.(1965). Optimal technical change in an aggregative model of economic growth. International Economic Review, 6(January), $18-31$. 


\section{APPENDIX}

(1) $Y=A K^{\alpha} G_{1}^{\beta}\left(L G_{2}\right)^{1-\alpha-\beta}$

$$
\begin{aligned}
& y=A(k)^{\alpha}\left(g_{1}\right)^{\beta}\left(G_{2}\right)^{1-\alpha-\beta} \\
& \mathrm{MP}_{\mathrm{K}}=\frac{\partial Y}{\partial K}=L \cdot A \cdot g_{1}^{\beta} \cdot G_{2}^{1-\alpha-\beta} \cdot \alpha k^{\alpha-1} \cdot \frac{\partial k}{\partial K}=A g_{1}^{\beta} \cdot G_{2}{ }^{1-\alpha-\beta} \cdot \alpha k^{-(1-\alpha)} \\
& G_{1}+G_{2}=G=(1-\psi) r \cdot Y \\
& G_{1}=\lambda(1-\psi) r \cdot Y \text { and } G_{2}=(1-\lambda)(1-\psi) r \cdot y \\
& g_{1}=\frac{G_{1}}{L}=\frac{1}{L} \cdot \lambda(1-\psi) r \cdot Y
\end{aligned}
$$

Putting the value of $Y$ from equation (1) in $\mathrm{G}_{2}$ we get

$$
G_{2}=(1-\lambda)(1-\psi) r \cdot A K^{\alpha} G_{1}{ }^{\beta}\left(L G_{2}\right)^{1-\alpha-\beta}
$$

or, $\frac{G_{2}}{G_{2}{ }^{1-\alpha-\beta}}=(1-\lambda)(1-\psi) r . A K^{\alpha} G_{1}{ }^{\beta} L^{1-\alpha-\beta}$

or, $G_{2}=\left[(1-\lambda)(1-\psi) r . A K^{\alpha} G_{1}^{\beta} G_{1}^{\beta}\right]^{\frac{1}{\alpha+\beta}}$

After simplification, we get

(2) $G_{2}=\{(1-\lambda)(1-\psi) r . A\}^{\frac{1}{\alpha+\beta}} k^{\frac{\alpha}{\alpha+\beta}} L^{\frac{1-\alpha-\beta}{\alpha+\beta}} G_{1}^{\frac{\beta}{\alpha+\beta}}$

In the same way, putting the value of $Y$ in $\mathrm{G}_{1}$ we get

$$
G_{2}=\lambda(1-\psi) r . A K^{\alpha} G_{1}^{\beta}\left(L G_{2}\right)^{1-\alpha-\beta}
$$

Following the same procedure as in $\mathrm{G}_{2}$ we get

$$
\text { (3) } \begin{aligned}
G_{1} & =\{\lambda(1-\psi) r \cdot A\}^{\frac{1}{\alpha-\beta}} \cdot k^{\frac{\alpha}{1-\beta}} \cdot L^{\frac{1-\beta}{1-\beta}} \cdot G_{2}^{\frac{1-\alpha-\beta}{1-\beta}} \\
g_{1} & =\frac{G_{1}}{L}=\{\lambda(1-\psi) r A\}^{\frac{1}{1-\beta}} \cdot k^{\frac{\alpha}{1-\beta}} \cdot G_{2}^{\frac{1-\alpha-\beta}{1-\beta}}
\end{aligned}
$$

Now, putting the value of $\mathrm{G}_{2}$ from (2) in $\mathrm{G}_{1}$ we get,

$$
G_{1}=\{\lambda(1-\psi) r A\}^{\frac{1}{1-\beta}} \cdot k^{\frac{\alpha}{1-\beta}} \cdot L^{\cdot}\left[\{(1-\lambda)(1-\psi) r A\}^{\frac{1}{\alpha+\beta}} \cdot k^{\frac{\alpha}{\alpha+\beta}} \cdot L^{\frac{1-\beta}{\alpha+\beta}}\right]^{\frac{1-a-\beta}{1-\beta}} \cdot G_{1}^{\frac{\beta}{\alpha+\beta} \frac{1-\alpha-\beta}{1-\beta}}
$$


After simplification, $G_{1}$ is expressed as

(4) $G_{1}=\lambda^{\frac{\alpha+\beta}{\alpha}}[(1-\psi) r A]^{\frac{1}{\alpha}}(1-\lambda)^{\frac{1-\alpha-\beta}{\alpha}} \cdot L^{\frac{1-\beta}{\alpha+\beta}} k$

Again putting the value of $\mathrm{G}_{1}$ from (4) in $\mathrm{G}_{2}$ in (2) we get

(5) $G_{2}=\{(1-\lambda)(1-\psi) r A\}^{\frac{1}{\alpha+\beta}} \cdot k^{\frac{\alpha}{\alpha+\beta}} \cdot L^{\frac{1-\beta}{\alpha+\beta}} \cdot\left\{\lambda^{\frac{\alpha+\beta}{\alpha}}[(1-\psi) r A]^{\frac{1}{\alpha}}(1-\lambda)^{\frac{1-\alpha-\beta}{\alpha}} \cdot L^{\frac{1-\beta}{\alpha}} \cdot k\right\}^{\frac{\beta}{\alpha+\beta}}$

Simplification of (5) gives

(6) $G_{2}=\lambda^{\frac{\beta}{\alpha}} \cdot(1-\lambda)^{\frac{\alpha+\beta(1-\varepsilon-\beta)}{\alpha(\alpha+\beta)}} \cdot[(1-\psi) r A]^{\frac{1}{\alpha}} \cdot L^{\frac{1-\beta}{\alpha}} \cdot k$

Substituting the values of $\mathrm{g}_{1}$ and $\mathrm{G}_{2}$ in $\mathrm{MP}_{\mathrm{K}}$ from (4) and (6) respectively, and after simplification, we get

$$
\mathrm{MP}_{\mathrm{K}}=\alpha A^{\frac{1}{\alpha}} \cdot \lambda^{\frac{\beta}{\alpha}} \cdot(1-\lambda)^{\frac{1-\alpha-\beta}{\alpha}}[(1-\psi) r]^{\frac{1-\alpha}{\alpha}} \cdot \mathrm{L}^{\frac{\beta}{\alpha}}
$$

